\title{
CONSIDERACIONES ADICIONALES ACERCA DEL PROCESO DE UNIFICACIÓN DEL VALLE DEL NILO*
}

\author{
Marcelo Campagno**
}

\begin{abstract}
En el número anterior de la Rev. do Museu de Arqueologia e Etnologia, consideramos las características del proceso de expansión política de los "protoEstados" surgidos en el Alto Egipto en la segunda mitad del IV milenio a.C., que desemboca en la unificación del territorio comprendido entre la primera catarata del Nilo y el Mar Mediterráneo, hacia el 3000 a.C. (Campagno 2002b: 123-141). Dos mapas adicionales y unas consideraciones marginales intentan expandir - apenas un poco más-la reflexión acerca de las características centrales de tal proceso.

Ciertamente, el proceso en el que adviene la unificación sociopolítica del valle del Nilo presenta múltiples aristas. Una de ellas refiere a la dinámica étnica asociada a tal proceso político. El abordaje de esta cuestión es en extremo difícil, dadas las limitaciones de la evidencia disponible. Sin embargo, es posible proponer algunas reflexiones, que surgen en el marco de una investigación en curso. Si las prácticas interétnicas son básicamente prácticas de la diferencia, esto implica que, para que haya etnicidad, debe haber interacción entre grupos que exhiben y perciben características culturales divergentes (cf., por ejemplo, Eriksen 2002 [1993]; desde el punto de vista arqueológico, Jones 1997; en relación con la situación que aquí nos ocupa, Kansa y Levy 2002: 199-201). En tal sentido, hacia mediados del IV milenio a.C., se advierten ciertas divergencias entre las características culturales
\end{abstract}

(*) In Rev. do Museu de Arqueologia e Etnologia, 12, 2002, we have considered the characteristics of the process of political expansion of the "proto-states" emerged in Upper Egypt, in the second half of IV millennium B.C., which conduces to the unification of the whole territory from the First Cataract of the Nile to the Mediterranean Sea. Two additional maps and some marginal considerations about ethnicity are proposed here, in order to expand the reflection about such a process just a little more.

$\left({ }^{* *}\right)$ Universidad de Buenos Aires, Argentina. del sur y del norte - el área entre Hieracómpolis y Abidos y el área del delta - que es posible interpretar en clave de etnicidad.

\section{I.}

Si bien es probable que, desde el $\mathrm{V}$ milenio, incluso antes, el valle y el delta del Nilo hayan participado de un mismo macro-ambiente cultural (un tipo genéricamente similar de organización socioeconómica aldeana, algunos criterios funerarios compatibles, quizá también un idioma genéricamente similar, de raíz afroasiática), dos grandes grupos culturales se recortan de esa suerte de homogeneidad básica: se trata de las culturas de Nagada en el sur y de Buto-Maadi en el norte. Las principales divergencias se advierten en el plano de las prácticas funerarias (diferente orientación de los cadáveres, diverso énfasis en la colocación de ofrendas funerarias), de los objetos de la cultura material (especialmente, los tipos cerámicos), y de algunos rasgos fenotípicos (cf. Trigger 1985 [1983]: 46; Kemp 1995: 682-683; Cialowicz 2001: 7-8; Campagno 2002a: 149; Smith, 2002, 118-122). Dado que, especialmente por la vía de los intercambios, las poblaciones del norte y del sur mantuvieron ciertos contactos entre sí, es posible suponer que el reconocimiento de mayores afinidades culturales entre las comunidades vecinas respecto de los rasgos compartidos con las comunidades más lejanas haya conducido a cierta interpretación de tales identidades y diferencias en clave étnica, aun cuando no sea posible establecer fehacientemente el modo específico en el que tales diferencias podían ser interpretadas por cada uno de los grupos.

II.

Desde el punto de vista de la etnicidad, el proceso sociopolítico que se desencadena en el 
Alto Egipto durante la fase Nagada IIc-d (aprox. 3400-3200 a.C.) resulta de suma importancia, tanto por los efectos que produce en la propia región como por los que genera en la región del delta. En primer lugar, a la escala regional, los conflictos que conducen a la unificación política producen, por primera vez, un tipo de integración sociopolítica que coincidiría grosso modo con los límites del grupo étnico. En efecto, los conflictos iniciales que conducen a la formación de los primeros proto-Estados oponían a comunidades cuyo principal criterio para diferenciarse entre sí procedía del hecho que constituir diferentes redes parentales. Por su parte, los conflictos que se continúan a la escala de los proto-Estados opondrían luego a diferentes redes articuladas por medio de prácticas estatales. Pero, en ambas situaciones, esos enfrentamientos se producen dentro de un mismo ámbito cultural, que interpretamos aquí en clave de etnicidad. En tal sentido, pues, el proceso de conflictos que conduce al Estado conduce también, en los inicios de la fase Nagada III (hacia 3200 a.C.), a la unificación sociopolítica del mismo espacio étnico. Por primera vez, los límites estatales coincidirían con los límites étnicos.

\section{III.}

Paralelamente a la constitución de una entidad sociopolítica que en el sur alcanza los límites del grupo étnico, en el delta se produce una serie de cambios que parecen alterar sensiblemente las dinámicas culturales preexistentes. En efecto, a comienzos de la fase Nagada III, los testimonios procedentes del delta del Nilo indican un decisivo proceso de reorientación cultural en el Bajo Egipto. Es posible suponer que los sitios que, desde el comienzo, ofrecen un tipo de cultura material asociada al Alto Egipto (Abusir el-Melek, Minshat Abu Omar) hayan tenido una composición étnica mayormente altoegipcia. La variación gradual o repentina de la cultura material en los sitios del horizonte de Buto-Maadi, en cambio, resulta más difícil de interpretar. En todo caso, está claro que semejante viraje cultural - incluso por el hecho mismo de su simultaneidad en una considerable cantidad de sitios del delta - hubo de darse en el marco de la intensificación de los contactos interétnicos entre el norte y el sur.

Ahora bien, esos contactos interétnicos, ¿hasta qué punto pudieron producir variaciones en las características étnicas de los habitantes del delta? No es posible responder a tal cuestión de una manera estricta. Por un lado, es cierto que los principales marcadores culturales del horizonte Buto-Maadi que se hallan a nuestro alcance (básicamente, criterios para la elaboración de cerámica y prácticas funerarias) se disuelven y dejan a paso a criterios procedentes del sur. Pero, por el otro lado, la identidad étnica de los habitantes del delta pudo reconocerse también a partir de otras marcas. Algunas de ellas, quizá podrían haber sido más compatibles desde el principio con aquellas del sur (como podría haber sucedido en relación con las representaciones del mundo o, incluso, con la lengua utilizada por ambos grupos). Otras, en cambio, podrían haber enfatizado diferencias (rasgos fenotípicos, costumbres locales), aun cuando sean muy difícil de documentar arqueológicamente. En tales condiciones, es difícil de pronunciarse acerca del status étnico de los habitantes del delta hacia fines de la fase Nagada II. Pero, en todo caso, es posible reconocer que el proceso de expansión de las prácticas culturales sureñas, en el marco de la intensificación de los contactos interétnicos, debió incidir - en una escala imposible de precisar - en una mayor aproximación de las culturas del delta y del valle y que - en la medida en que tales prácticas culturales constituyen marcadores de etnicidad - esa aproximación no pudo resultar indiferente a los modos en que, hasta entonces, podían reconocerse las diferencias étnicas entre uno y otro grupo.

\section{IV.}

Hayan subsistido o no particularidades étnicas regionales en el ámbito políticamente unificado, desde que ésta se alcanza y a lo largo de las épocas posteriores, el Estado propondrá una imagen de identidad étnica homogénea para los habitantes del territorio bajo su control que se contrasta ante los habitantes de las periferias, identificados siempre bajo un común denominador de negatividad. En efecto, si bien el Estado reconocería ciertas diferencias étnicas entre los habitantes del mundo exterior - libios, nubios y asiáticos, distinguidos a partir de sus rasgos fenotípicos, vestimentas y otras prácticas culturales -, todos ellos serán vistos, en conjunto, como los no-egipcios, los Otros frente a los cuales se elaboran los criterios de pertenencia intraétnica. De hecho, la elaboración de una 


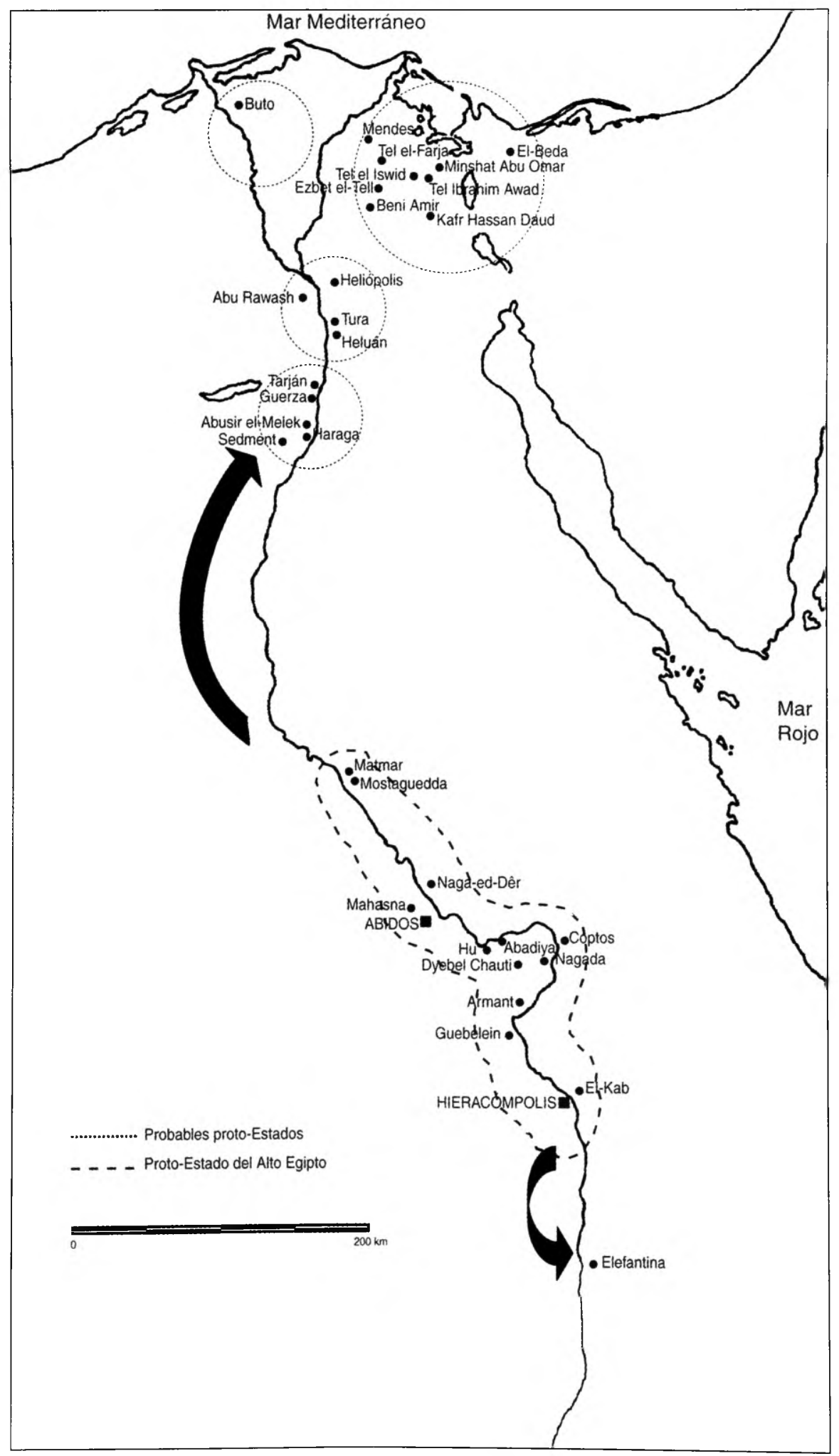




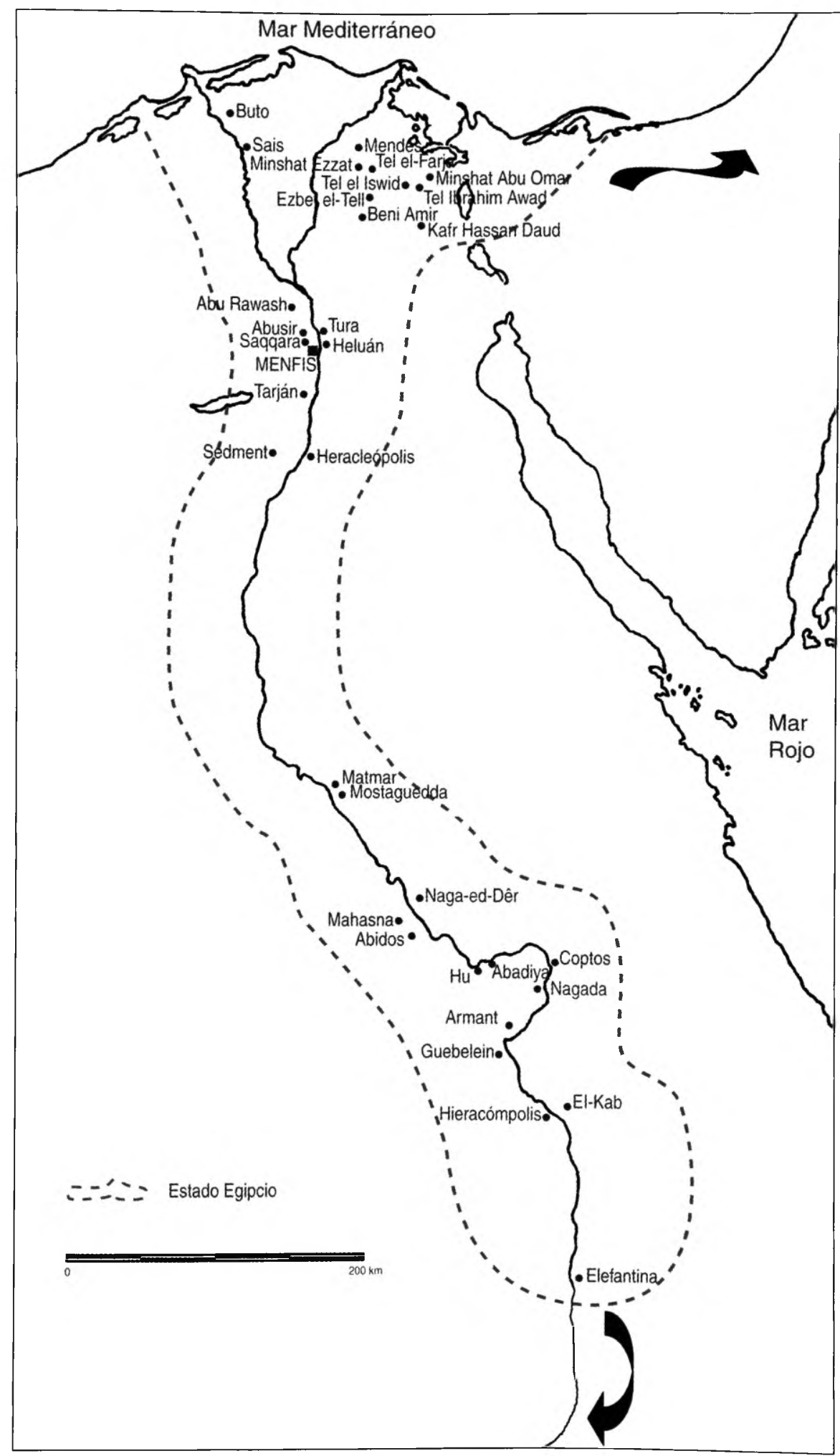


identidad étnica-estatal - vale decir, de una dimensión política de la etnicidad - tendió a asociar la condición negativa inherente al Otro étnico con una condición de enemigo del Estado. Como señala Wilkinson (2002: 518), "la ideología estatal buscó definir Egipto y el modo de vida egipcio contrastándolo no con animales salvajes [como en la época previa] sino con extranjeros. Así, desde el comienzo de la Dinastía I, el 'enemigo es descripto como un 'bárbaro' subyugado" En efecto, con la intervención del Estado en la esfera de la etnicidad, las marcas que se perciben en clave de diferenciación étnica tienden a connotar también una diferenciación política. Y desde las coordenadas simbólicas específicas a partir de las que el Estado egipcio lee el afuera, esa negatividad política, por oposición a un Egipto ordenado, se transforman en manifestación del caos: esos 'bárbaros' serían, más específicamente, emisarios del caos y, por ello, enemigos de Egipto.
En todo caso, si hacia el 3200 a.C., con la unificación del sur podría haberse asistido a una primera unificación política del mismo ámbito étnico, esa coincidencia entre ámbito étnico y ámbito político podría haber sido un criterio de primera magnitud para la posterior expansión política hacia el norte. En efecto, si el viraje cultural del norte hubiera tendido a aproximar étnicamente ambas regiones, la posterior expansión del Estado sureño podría haber perseguido - entre otros fines - una nueva coincidencia entre los espacios político y étnico. Ciertamente, esta nueva coincidencia se producía ahora a una escala sin precedentes. Y esa escala - tanto en el plano étnico como en el político - era efecto de la potencia expansiva de la práctica estatal surgida en el sur. Hacia el 3000 a.C., con la concreción de tal expansión, se abrían las puertas para la plasmación de una identidad étnica específicamente egipcia, cuyas características más generales permanecerían a lo largo de más de tres milenios.

\section{Referencias bibliográficas}

\section{CAMPAGNO, $\mathrm{M}$.}

2002a De los jefes-parientes a los reyes-dioses. Surgimiento y consolidación del Estado en el Antiguo Egipto. Aula Ægyptiaca-Studia, 3. Barcelona, Aula Ægyptiaca.

2002b Los "proto-Estados" del Alto Egipto y la unificación del valle del Nilo. Rev. do Museu de Arqueología e Etnología, 12: 123-141.

CIALOWICZ, $\mathrm{K}$.

2001 La naissance d'un royaume. L'Egypte dès la période prédynastique à la fin de la lère dynastie. Krakow: Ksiegarnia Akademicka.

ERIKSEN, TH.

2002 Ethnicity and Nationalism. London: Pluto

[1993] Press.

JONES, $S$.

1997 The Archaeology of Ethnicity. Constructing identities in the past and present. London: Routledge.

KANSA, E.; LEVY, TH.

2002 Ceramics, Identity and the Role of the State: The View from Nahal Tillah. E. van den Brink; Th. Levy (Eds.) Egypt and the Levant. Interrelations from the $4^{\text {th }}$ through the Early $3^{\text {rd }}$ Millennium B.C.E. London, Leicester University Press: 190-212.
KEMP, B.

1995 Unification and Urbanization of Ancient Egypt. J. Sasson (Ed.) Civilizations of the Ancient Near East, 1. New York, Charles Scribner's Sons: 679-690.

SMITH, P.

2002 The Palaeo-Biological Evidence for Admixture between Populations in the Southern Levant and Egypt in the Fourth to Third Millennia BCE. E. van den Brink; Th. Levy (Eds.) Egypt and the Levant. Interrelations from the $4^{\text {th }}$ through the Early $3^{r d}$ Millennium B.C.E. London, Leicester University Press.: 118-128.

TRIGGER, B.

1985 Los comienzos de la civilización egipcia.

[1983] B.Trigger; B. Kemp; D. O’Connor; A. Lloyd Historia del Antiguo Egipto. Barcelona, Crítica: 15-97.

WILKINSON, T.

2002 Reality versus Ideology: The Evidence for 'Asiatics' in Predynastic and Early Dynastic Egypt. E. van den Brink; Th. Levy (Eds.) Egypt and the Levant. Interrelations from the $4^{\text {th }}$ through the Early $3^{\text {rd }}$ Millennium B.C.E. London, Leicester University Press: 514-520. 